JOURNAL OF PHYSICS AND CHEMISTRY OF SOLIDS

\title{
Temperature dependence of the luminescence of nanocrystalline $\mathrm{CdS} / \mathrm{Mn}^{2+}$
}

\author{
Ageeth A. Bol*, Rick van Beek, Joke Ferwerda, Andries Meijerink \\ Physics and Chemistry of Condensed Matter, Debye Institute, Utrecht University, P.O. Box 80 000, 3508 TA Utrecht, The Netherlands
}

Received 29 October 2001; received in revised form 13 May 2002; accepted 14 May 2002

\begin{abstract}
The temperature dependence of the luminescence properties of nanocrystalline $\mathrm{CdS} / \mathrm{Mn}^{2+}$ particles is investigated. In addition to an orange $\mathrm{Mn}^{2+}$ emission around $585 \mathrm{~nm}$ a red defect related emission around $700 \mathrm{~nm}$ is observed. The temperature quenching of both emissions is similar $\left(T_{\mathrm{q}} \approx 100 \mathrm{~K}\right)$. For the defect emission the reduction in the lifetime follows the temperature dependence of the intensity. For the $\mathrm{Mn}^{2+}$ emission however, the intensity decreases more rapidly than the lifetime with increasing temperature. To explain these observations a model is proposed in which the $\mathrm{Mn}^{2+}$ ions are excited via an intermediate state involving shallowly trapped $(\approx 40 \mathrm{meV})$ charge carriers.
\end{abstract}

(C) 2002 Elsevier Science Ltd. All rights reserved.

Keywords: A. Nanostructures; A. Semiconductors; D. Luminescence

\section{Introduction}

Nowadays, it is well known that the electronic properties of nanocrystalline semiconductors change with decreasing particle size due to quantum confinement effects [1-5]. If the radius of the semiconductor particles becomes smaller than the Bohr radius of the exciton the band gap of the semiconductor increases and the edges of the bands split into discrete energy levels. In the last two decades these quantum confinement effects have stimulated great interest in both basic and applied research.

The luminescence of $\mathrm{Mn}^{2+}$ ions in quantum sized nanocrystalline sulphides like $\mathrm{ZnS}$ became a popular field of research after it was reported that nanocrystalline $\mathrm{ZnS} / \mathrm{Mn}^{2+}$ yields high luminescence quantum yields and lifetime shortening at the same time due to quantum confinement effects [6]. Even though it was shown later that the lifetime shortening of the $\mathrm{Mn}^{2+}$ emission in nanocrystalline $\mathrm{ZnS} / \mathrm{Mn}^{2+}$ was due to a misinterpretation $[7,8]$, the luminescence of various luminescent ions in different II-VI semiconductors

\footnotetext{
* Corresponding author. Present address: Philips Research, Prof. Holstlaan 4 (WA11), 5656 AA Eindhoven, The Netherlands. Tel.: +31-40-2742271; fax: +31-30-2744282.

E-mail address: ageeth.bol@philips.com (A.A. Bol).
}

has been studied extensively. One of the systems that have been investigated is nanocrystalline $\mathrm{CdS} / \mathrm{Mn}^{2+}[9-13]$. In nanocrystalline $\mathrm{CdS} / \mathrm{Mn}^{2+}$ both an orange $(585 \mathrm{~nm})$ emission and a red emission $(\sim 700 \mathrm{~nm})$ have been observed. The orange emission has been assigned to the ${ }^{4} \mathrm{~T}_{1} \rightarrow{ }^{6} \mathrm{~A}_{1}$ transition on $\mathrm{Mn}^{2+}$ and the red emission to defects in CdS. The lifetime of the $\mathrm{Mn}^{2+}$ related emission is in the ms range [9-11], in agreement with the long ms lifetime observed for $\mathrm{Mn}^{2+}$ in nanocrystalline $\mathrm{ZnS} / \mathrm{Mn}^{2+}[7,8]$.

Some groups have proposed models on the mechanism of luminescence for nanocrystalline $\mathrm{CdS} / \mathrm{Mn}^{2+}$. Levy et al. [12] suggested that after excitation of the nanocrystalline CdS host, energy will be transferred from the conduction band of the CdS host to the ${ }^{4} \mathrm{~T}_{1}$ level of the $\mathrm{Mn}^{2+}$ impurity or to defect states, resulting in emissions around 590 and $700 \mathrm{~nm}$, respectively. Liu et al. [13] proposed that after host lattice excitation the excited charge carriers are trapped rapidly by localised surface states, followed by energy transfer from these surface states to the ${ }^{4} \mathrm{~T}_{1}$ level of the $\mathrm{Mn}^{2+}$ impurity, from which radiative decay to the ${ }^{6} \mathrm{~A}_{1}$ ground state of the $\mathrm{Mn}^{2+}$ ion occurs.

To investigate the mechanism of luminescence for nanocrystalline $\mathrm{CdS} / \mathrm{Mn}^{2+}$ in more detail this report deals with temperature dependent luminescence and lifetime measurements on nanocrystalline $\mathrm{CdS} / \mathrm{Mn}^{2+}$ and $\mathrm{Cd}_{x} \mathrm{Zn}_{1-x} \mathrm{~S} / \mathrm{Mn}^{2+}$. 


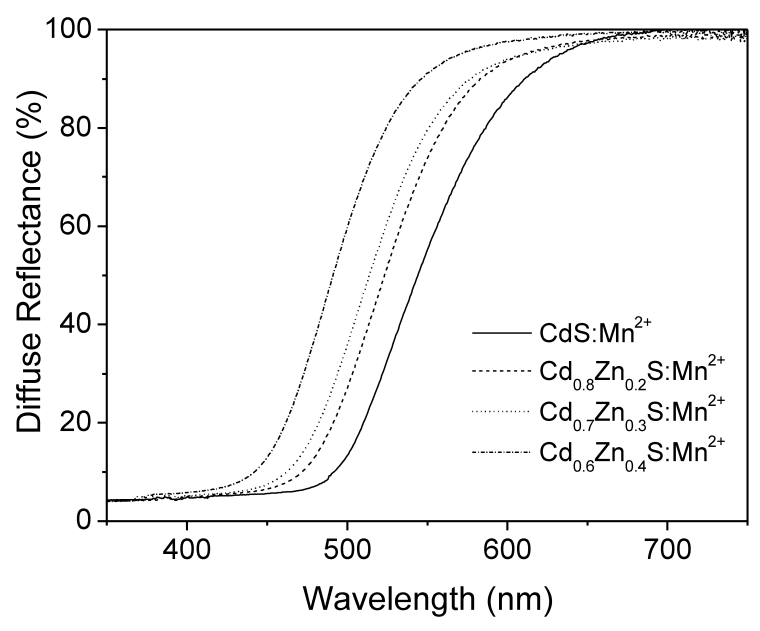

Fig. 1. UV-VIS reflection spectra of nanocrystalline $\mathrm{Cd}_{x} \mathrm{Zn}_{1-x} \mathrm{~S} /$ $\mathrm{Mn}^{2+}$.

\section{Experimental}

The synthesis route followed to make nanocrystalline $\mathrm{CdS} / \mathrm{Mn}^{2+}$ resembles standard methods for synthesis of nanocrystalline II-VI semiconductors. The method used for the synthesis of nanocrystalline $\mathrm{CdS} / \mathrm{Mn}^{2+}$ coated with sodiumpolyphosphate (PP) is very similar to the one we used for the synthesis of nanocrystalline $\mathrm{ZnS} / \mathrm{Mn}^{2+}$ and $\mathrm{ZnS} / \mathrm{Pb}^{2+}[7,14]$. Ten millilitre, $1 \mathrm{M} \mathrm{Cd}\left(\mathrm{ClO}_{4}\right)_{2} \cdot 6 \mathrm{H}_{2} \mathrm{O}$ and 10 or $25 \mathrm{ml} 0.1 \mathrm{M} \mathrm{Mn}\left(\mathrm{ClO}_{4}\right)_{2} \cdot 6 \mathrm{H}_{2} \mathrm{O}$ were added to an aqueous solution of $10.2 \mathrm{~g} \mathrm{Na}\left(\mathrm{PO}_{3}\right)_{n}$ (Aldrich, 96\%, $n \sim 10$ ). The total volume after the addition was $90 \mathrm{ml}$. After about $10 \mathrm{~min}$ of stirring, $10 \mathrm{ml}$ of a $1 \mathrm{M} \mathrm{Na}_{2} \mathrm{~S} \cdot 9 \mathrm{H}_{2} \mathrm{O}$ solution was injected into the solution. Immediately after the injection of the $\mathrm{Na}_{2} \mathrm{~S}$ solution a turbid orange fluid was obtained. Then the particles were centrifuged, rinsed with distilled water and ethanol, and dried in vacuum. Samples of $\mathrm{Cd}_{x} \mathrm{Zn}_{1-x} \mathrm{~S} / \mathrm{Mn}^{2+}$ were prepared in the same way as ascribed earlier. The only difference is that $10 x \mathrm{ml}$ of $1 \mathrm{M}$ $\mathrm{Cd}\left(\mathrm{ClO}_{4}\right)_{2} \cdot 6 \mathrm{H}_{2} \mathrm{O}$ and $10(1-x) \mathrm{ml}$ of $1 \mathrm{M} \mathrm{Zn}\left(\mathrm{ClO}_{4}\right)_{2} \cdot 6 \mathrm{H}_{2} \mathrm{O}$ was used instead of $10 \mathrm{ml}$ of $1 \mathrm{M} \mathrm{Cd}\left(\mathrm{ClO}_{4}\right)_{2} \cdot 6 \mathrm{H}_{2} \mathrm{O}$.

$\mathrm{X}$-ray powder diffraction patterns of the samples were obtained with a Philips PW 1729 X-ray generator with $\mathrm{Cu} \mathrm{K} \alpha$ radiation $(\lambda=1.542 \AA)$. From the line width the particle diameter was calculated using the Scherrer formula [15]. Diffuse reflection spectra were measured using a double beam Perkin-Elmer Lambda 16 UV/VIS spectrophotometer.

Emission and excitation spectra were recorded on a SPEX Fluorolog spectrophotometer model F2002, equipped with two double grating $0.22 \mathrm{~m}$ monochromators (SPEX 1680 ) and a $450 \mathrm{~W}$ Xenon lamp as excitation source. The emission was detected with a cooled Hamamatsu R928 photomultiplier. In some cases an ARC Spectro Pro ${ }^{\circledR}-300 \mathrm{i}$ monochromator and a Princeton Instruments CCD camera were used to measure emission spectra.
For lifetime measurements at an excitation wavelength of $355 \mathrm{~nm}$ the third harmonic of a Quanta Ray Nd/YAG laser was used. The emission was detected by an ARC Spectro Pro ${ }^{\circledR}-300 \mathrm{i}$ monochromator and a RCA c31034 photomultiplier tube or by a Spex $12691.26 \mathrm{~m}$ monochromator and a Hamamatsu R928P photomultiplier (thermoelectrically cooled to $-30^{\circ} \mathrm{C}$ ).

Decay curves were measured with a Tektronix 2440 digital oscilloscope. Temperature dependent measurements were performed using an Oxford Instruments liquid helium flow cryostat for temperatures ranging from $4.2 \mathrm{~K}$ to room temperature.

\section{Results and discussion}

$\mathrm{UV}-\mathrm{Vis}$ reflection spectroscopy and X-ray diffraction have been used to study the absorption characteristics and size of the $\mathrm{CdS} / \mathrm{Mn}^{2+}$ and $\mathrm{Cd}_{x} \mathrm{Zn}_{1-x} \mathrm{~S} / \mathrm{Mn}^{2+}$ nanoparticles. Fig. 1 shows diffuse reflection spectra of nanocrystalline $\mathrm{CdS} / \mathrm{Mn}^{2+}$ and $\mathrm{Cd}_{x} \mathrm{Zn}_{1-x} \mathrm{~S} / \mathrm{Mn}^{2+}(x=1,0.8,0.7$ and 0.6). The onset of absorption (the point were the diffuse reflection becomes smaller than $100 \%$ ) is a measure for the size of the band gap of the semiconductor. For nanocrystalline CdS/ $\mathrm{Mn}^{2+}$ a broad absorption band with an absorption onset at $650 \mathrm{~nm}$ is observed. The tail in the absorption spectrum extends to longer wavelengths than for bulk CdS. This is probably due to sulphur or MnS contamination, which absorb in this region. The spectral position of the absorption maximum explains the orange colour of the sample. The position of the absorption band is very close to that of bulk $\mathrm{CdS}$. This is in agreement with the fact that the radius of the CdS particles $(\sim 2.5 \mathrm{~nm})$ is similar to the exciton Bohr radius $(2.5 \mathrm{~nm})$ in $\mathrm{CdS}$. In this size regime only weak quantum size effects are present.

The band gap of bulk CdS is smaller $(2.5 \mathrm{eV})$ than the band gap of bulk $\mathrm{ZnS}$ (3.7 eV) [16]. By admixing small amounts of $\mathrm{Zn}$ into the $\mathrm{CdS}$ lattice the band gap of the system increases. This is also illustrated in Fig. 1. By admixing $0-40 \%$ of $\mathrm{Zn}^{2+}$ into the CdS lattice the band gap increases and the onset of the absorption band shifts to higher energies.

The XRD patterns of nanocrystalline $\mathrm{CdS} / \mathrm{Mn}^{2+}$ show broad bands due to the finite size of the nanocrystals. Due to the line broadening it is difficult to deduce whether the nanocrystals have the wurtzite or the zincblende structure of CdS. Both modifications have been reported for nanocrystalline $\mathrm{CdS}$, although the zincblende structure is the most common modification for nanoparticles prepared in solution. From the line broadening of the XRD pattern the average particle diameter was calculated using Scherrer's formula [15]. The average particle diameter was around $4.5 \mathrm{~nm}$ for all samples.

In Fig. 2 a typical example of an emission and excitation spectrum of nanocrystalline $\mathrm{CdS} / \mathrm{Mn}^{2+}$ measured at $4 \mathrm{~K}$ is 


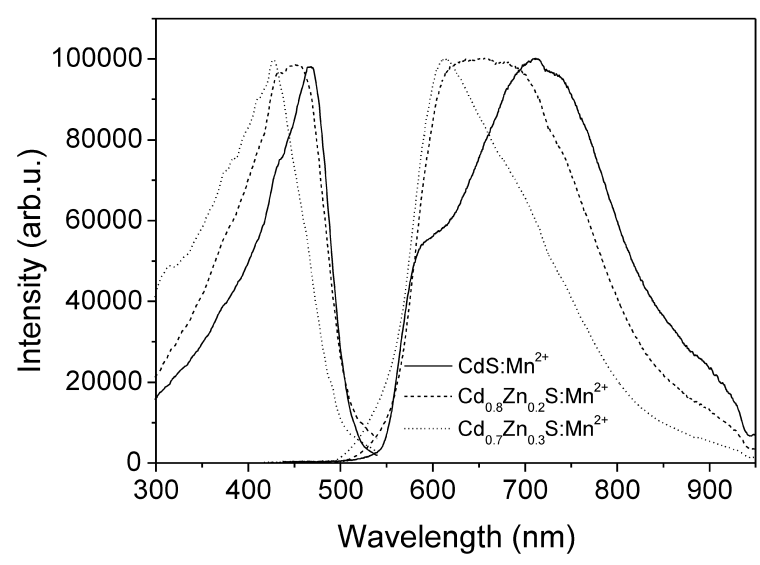

Fig. 2. Excitation and emission spectra of nanocrystalline $\mathrm{Cd}_{x-}$ $\mathrm{Zn}_{1-x} \mathrm{~S} / \mathrm{Mn}^{2+}(x=0,0.8$ and 0.7 , respectively) measured at $4 \mathrm{~K}$. The excitation spectra were measured for an emission wavelength of 585,595 and $595 \mathrm{~nm}$, respectively. The emission spectra were recorded for 450,450 and $425 \mathrm{~nm}$ excitation, respectively.

shown. The emission spectrum shows a broad band extending from 500 to $850 \mathrm{~nm}$. The shoulder at about $585 \mathrm{~nm}$ corresponds to the ${ }^{4} \mathrm{~T}_{1} \rightarrow{ }^{6} \mathrm{~A}_{1}$ transition of the $\mathrm{Mn}^{2+}$ impurity [17]. The emission around $700 \mathrm{~nm}$ is also observable for undoped nanocrystalline $\mathrm{CdS}$ and is assigned to a defect related CdS emission [18]. The excitation spectrum has its maximum around $450 \mathrm{~nm}$ and has shifted to the blue compared to the excitation spectrum of bulk CdS due to quantum confinement effects.

Fig. 2 also shows the excitation and emission spectra of several $\mathrm{Cd}_{x} \mathrm{Zn}_{1-x} \mathrm{~S} \mathrm{Mn}^{2+}\left(10 \% \mathrm{Mn}^{2+}\right.$ precursor concentration) samples measured at $4 \mathrm{~K}$. With increasing $\mathrm{Zn}^{2+}$ amount used in the synthesis the excitation spectrum shifts to the blue due to the increase of the band gap of the material, as was also illustrated in the diffuse reflection spectra (Fig. 1). The CdS related defect emission shifts to the blue accordingly, while the spectral position of the $\mathrm{Mn}^{2+}$ emission does not change, as far as can be deduced. The shift of the defect related emission in (nanocrystalline) semiconductors as the band gap changes indicates that a delocalised charge carrier is involved [19]. As the band gap changes, the energy of the delocalised (shallowly trapped) charge carrier follows the energy shift of the conduction or valence band and influences the wavelength of the emission band.

In Fig. 3 the temperature dependence of the emission of nanocrystalline CdS/ $\mathrm{Mn}^{2+}$ (25\% precursor concentration) is shown. With increasing temperature both the $\mathrm{Mn}^{2+}$ emission and the CdS related emission quench rapidly. Above $250 \mathrm{~K}$ the emission has totally quenched. The quenching temperature of the emission $\left(T_{\mathrm{q}}\right)$ is defined as the temperature at which the emission reaches half of its maximum intensity. Both the $\mathrm{Mn}^{2+}$ emission and the $\mathrm{CdS}$ related emission have a quenching temperature of $100 \mathrm{~K}$.

By admixing $\mathrm{Zn}^{2+}$ into the host lattice the temperature

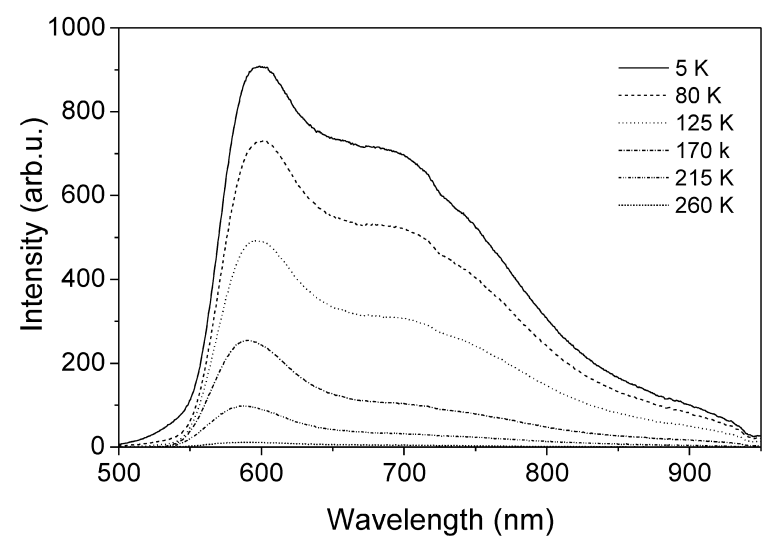

Fig. 3. Temperature dependence of the emission spectrum of nanocrystalline $\mathrm{CdS} / \mathrm{Mn}^{2+}\left(25 \% \mathrm{Mn}^{2+}\right.$ precursor concentration) measured for $455 \mathrm{~nm}$ excitation.

quenching of the emissions does not change: for all samples both emissions quench at the same rate (Fig. 4). For all $\mathrm{Cd}_{x} \mathrm{Zn}_{1-x} \mathrm{~S} / \mathrm{Mn}^{2+}$ samples quenching temperatures of around $100 \mathrm{~K}$ were found for both emissions. Similar temperature dependence has been reported for the $\mathrm{Mn}^{2+}$ emission of nanocrystalline $\mathrm{CdS} / \mathrm{Mn}^{2+}$ in Ref. [20]. A model that can explain the similar temperature dependence of the $\mathrm{Mn}^{2+}$ and the CdS related emission is shown in Fig. 5. After excitation in the CdS host (1) the excited charge carriers are trapped in shallow trap states. In Fig. 5 the situation is shown assuming that electrons are trapped in states just below the conduction band (2). A similar picture can be drawn for holes (based on the present results it is not possible to distinguish between the two possibilities). This trapping of charge carriers is followed by either energy transfer to the ${ }^{4} \mathrm{~T}_{1}$ excited state of a $\mathrm{Mn}^{2+}$ ion (3), or

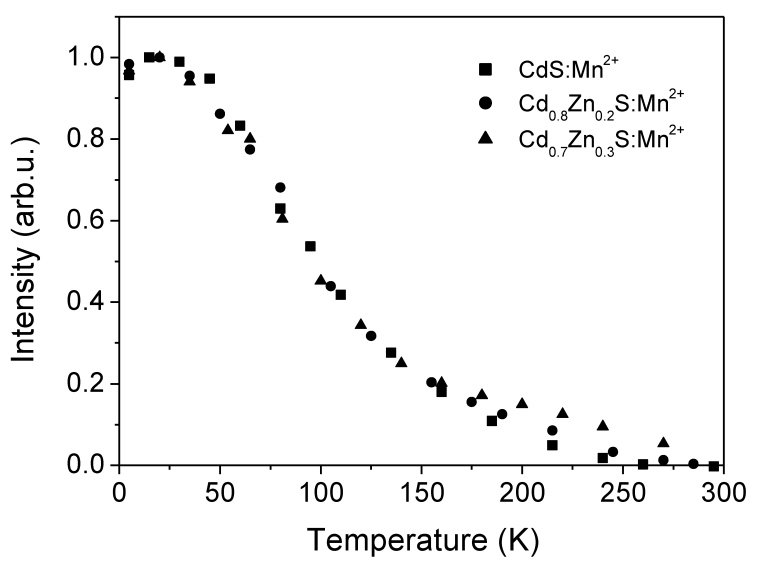

Fig. 4. Luminescence intensity of the $\mathrm{Mn}^{2+}$ emission $(600 \mathrm{~nm})$ as a function of temperature for nanocrystalline $\mathrm{CdS} / \mathrm{Mn}^{2+}, \mathrm{Cd}_{0.8} \mathrm{Zn}_{0.2-}$ $\mathrm{S} / \mathrm{Mn}^{2+}$ and $\mathrm{Cd}_{0.7} \mathrm{Zn}_{0.3} \mathrm{~S} / \mathrm{Mn}^{2+}\left(10 \% \mathrm{Mn}^{2+}\right.$ precursor concentration). The samples were excited 470,450 and $425 \mathrm{~nm}$, respectively. The curves are normalised at maximum luminescence intensity. 


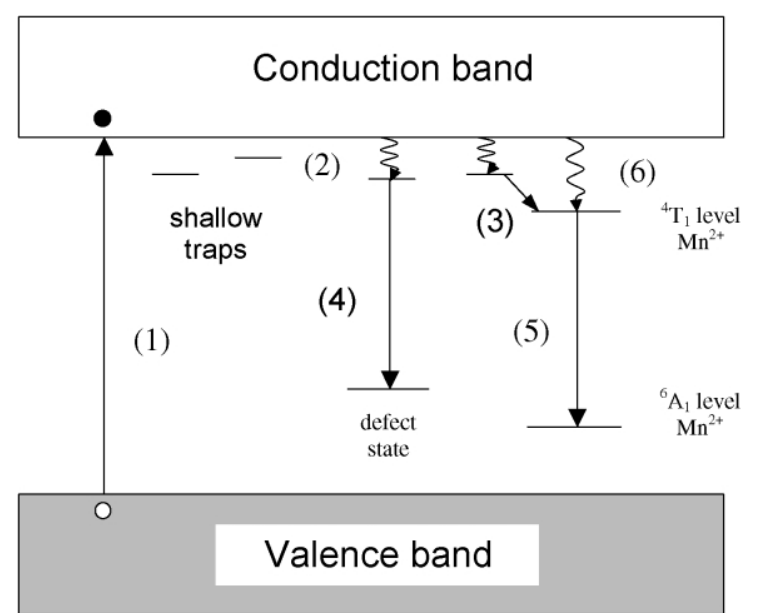

Fig. 5. Schematic representation of the proposed mechanism of the luminescence of nanocrystalline $\mathrm{CdS} / \mathrm{Mn}^{2+}$.

radiative recombination with a deeply trapped hole at a defect state (4) (CdS related emission at around $700 \mathrm{~nm})$. Step (3) is followed by radiative decay from the ${ }^{4} \mathrm{~T}_{1}$ excited state to the ${ }^{6} \mathrm{~A}_{1}$ ground state of the $\mathrm{Mn}^{2+}$ ion (5) giving the orange $\mathrm{Mn}^{2+}$ luminescence. With increasing temperature the shallow traps just below the conduction band are thermally emptied. This results in a decrease of both the defect related CdS emission and the $\mathrm{Mn}^{2+}$ emission in a similar way. If the ${ }^{4} \mathrm{~T}_{1}$ excited state of the $\mathrm{Mn}^{2+}$ ion was directly filled from the conduction band (6) the quenching temperature of the CdS emission and the $\mathrm{Mn}^{2+}$ related emission would be expected to be different.

By admixing $\mathrm{Zn}^{2+}$ into the host lattice the band gap of the material increases. This does not influence the quenching temperature of both emissions. From this it is concluded that the shallow traps shift with the conduction band to higher energies as is usually observed for shallowly trapped charge carriers [19]. Furthermore, this is in agreement with the interpretation that the $\mathrm{Mn}^{2+}$ ion is excited via the shallow trap states and not directly from the conduction band. If the latter was true the quenching temperature of the $\mathrm{Mn}^{2+}$ emission would be influenced by the size of the band gap, since the $\mathrm{Mn}^{2+}$ energy levels are not expected to shift in energy by changes in band gap due to admixing small amounts of $\mathrm{Zn}$ in the CdS host lattice.

Using Arrhenius equation the activation energy needed to detrap the charge carriers from the shallow trap states to the conduction band was calculated from the temperature dependence of the emission intensity. An activation energy of $41 \mathrm{meV}( \pm 5 \mathrm{meV})$ was found for both emissions.

To investigate the luminescence mechanism of nanocrystalline $\mathrm{CdS} / \mathrm{Mn}^{2+}$ in more detail the lifetimes of both the $\mathrm{Mn}^{2+}$ emission and the CdS related emission were measured. In Fig. 6 typical decay curves measured for the $\mathrm{Mn}^{2+}$ emission and the CdS related emission are shown. The decay curves of both emissions were fitted with a oneexponential decay function, which gave satisfactory results

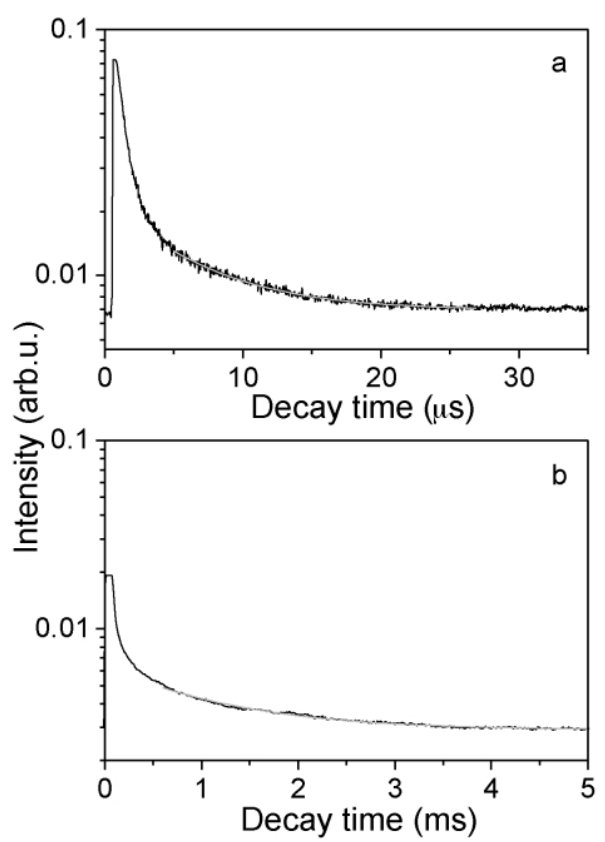

Fig. 6. Typical decay curves measured for nanocrystalline $\mathrm{CdS} / \mathrm{Mn}^{2+}\left(10 \% \mathrm{Mn}^{2+}\right.$ precursor concentration). The sample was excited at $355 \mathrm{~nm}$ and the decay curves were measured at an emission wavelength of (a) 710 and (b) 605 at $65 \mathrm{~K}$.

for the longer time regime. A non-exponential initial decay component is also present.

The temperature dependence of the lifetimes of both emissions of nanocrystalline $\mathrm{CdS} / \mathrm{Mn}^{2+}$ are shown in Fig. 7, together with the temperature dependence of the intensity of the emissions. The lifetime of the CdS related emission is about $6 \mu \mathrm{s}$ at $4 \mathrm{~K}$. At higher temperatures the decay time decreases to about $0.3 \mu \mathrm{s}$ at $150 \mathrm{~K}$. As can be seen in Fig. 7(a) the rate of the decrease of the lifetime of the CdS emission follows the decrease of the intensity of this emission. This is consistent with the previously proposed model in which it was assumed that the CdS related emission originates from shallow trap states. At elevated temperatures these trap states are thermally emptied, which causes a decrease of both the intensity and the lifetime of the emission at the same rate. Above $100 \mathrm{~K}$ the life time decreases faster with increasing temperature than the emission intensity. This indicates that in this temperature regime also the radiative decay rate is increased. This causes a drop in lifetime, without affecting the emission intensity.

The lifetime of the $\mathrm{Mn}^{2+}$ emission is approximately $1 \mathrm{~ms}$ at $4 \mathrm{~K}$ and comparable to the lifetime reported for the $\mathrm{Mn}^{2+}$ emission in bulk CdS/ $\mathrm{Mn}^{2+}(0.65 \mathrm{~ms}$ [21]). The lifetime is a factor of 2 smaller than the lifetime of the $\mathrm{Mn}^{2+}$ emission in nanocrystalline $\mathrm{ZnS} / \mathrm{Mn}^{2+}$ [7]. This can possibly be explained by the fact that the $\mathrm{Cd}^{2+}$ ion is heavier than the $\mathrm{Zn}^{2+}$ ion (average relative atomic masses 112.4 and 65.4, respectively [22]). An interaction between the heavy neighbouring $\mathrm{Cd}^{2+}$ ions (with a relative high spin-orbit 

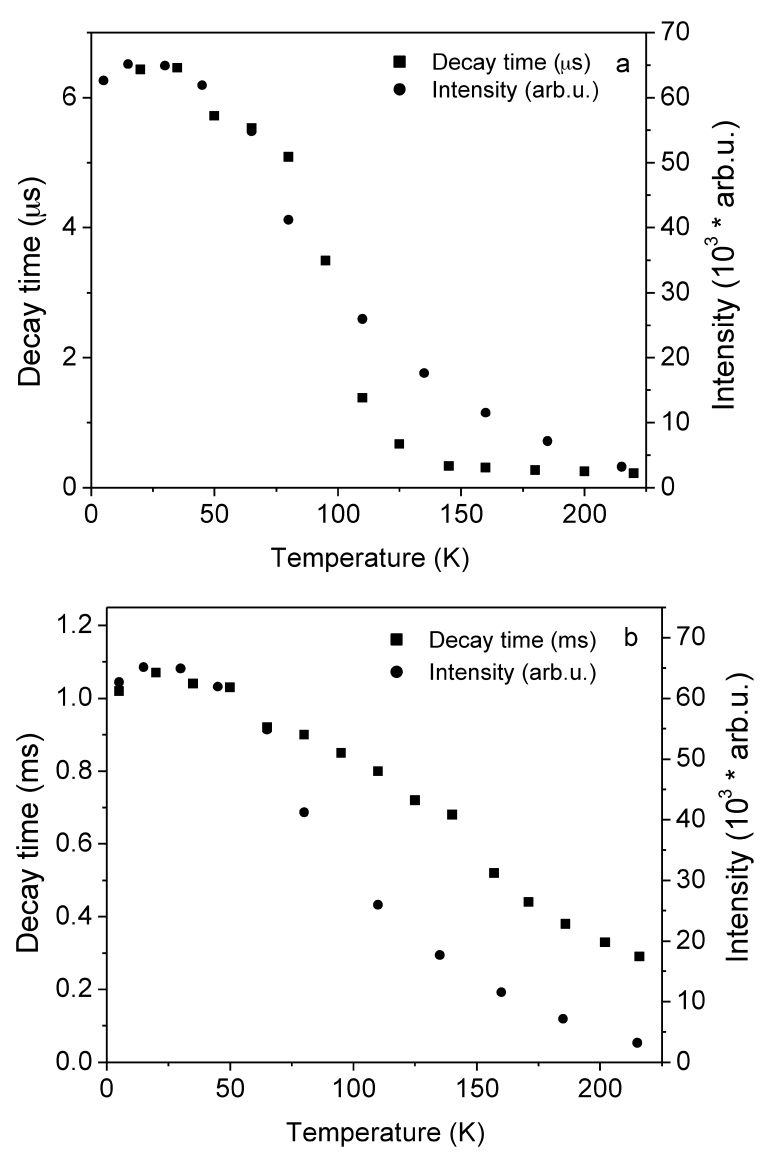

Fig. 7. Lifetime and intensity of (a) the CdS related emission $\left(\lambda_{\mathrm{em}}=\right.$ $710 \mathrm{~nm})$ and (b) the $\mathrm{Mn}^{2+}$ related emission $\left(\lambda_{\mathrm{em}}=605 \mathrm{~nm}\right)$ of nanocrystalline $\mathrm{CdS} / \mathrm{Mn}^{2+}\left(10 \% \mathrm{Mn}^{2+}\right.$ precursor concentration $)$ plotted as a function of temperature. For the decay time measurements the sample was excited with $355 \mathrm{~nm}$ radiation, while for the luminescence measurements $470 \mathrm{~nm}$ radiation was used.

coupling) and the $\mathrm{Mn}^{2+}$ luminescent centre can cause an increase of the spin-orbit coupling of the $\mathrm{Mn}^{2+}$ ion, which leads to relaxation of the spin selection rule. This causes a lower luminescent lifetime of the $\mathrm{Mn}^{2+}$ in CdS. This effect is analogous to the so-called external heavy atom effect [23] observed for organic molecules. By interaction between a heavy atom with a strong spin-orbit coupling (such as $\mathrm{I}^{-}$ [24], $\mathrm{Tl}^{+}[25]$ or rare earth ions [26]) the spin selection rule is partially lifted.

As can be seen in Fig. 7(b) the decay time of the $\mathrm{Mn}^{2+}$ emission decreases slower with increasing temperature than the emission intensity. This provides further evidence that the excited state of the $\mathrm{Mn}^{2+}$ ion $\left({ }^{4} \mathrm{~T}_{1}\right)$ is fed by the shallow delocalised traps from which the CdS related emission originates. The decrease of the intensity of the $\mathrm{Mn}^{2+}$ emission is then caused by the thermally activated emptying of the shallow traps. This process does not influence the lifetime of the $\mathrm{Mn}^{2+}$ emission. The decrease of the lifetime

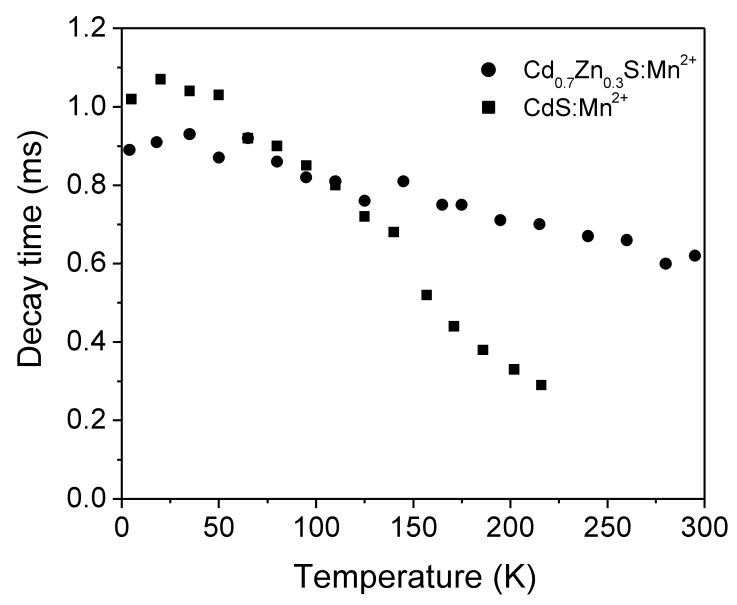

Fig. 8. Decay times of the $\mathrm{Mn}^{2+}$ emission $\left(\lambda_{\mathrm{em}}=600 \mathrm{~nm}\right)$ of nanocrystalline $\mathrm{CdS} / \mathrm{Mn}^{2+}$ and $\mathrm{Cd}_{0.7} \mathrm{Zn}_{0.3} \mathrm{~S} / \mathrm{Mn}^{2+}$ plotted as a function of temperature. The samples were excited at $355 \mathrm{~nm}$.

of the $\mathrm{Mn}^{2+}$ emission with increasing temperature is caused by an intrinsic quenching at the $\mathrm{Mn}^{2+}$ ion. Therefore the decrease of the luminescence intensity does not follow the reduction of the lifetime of the emission with temperature.

In Fig. 8 the lifetime of the $\mathrm{Mn}^{2+}$ emission of both nanocrystalline $\mathrm{CdS} / \mathrm{Mn}^{2+}$ and nanocrystalline $\mathrm{Cd}_{0.7} \mathrm{Zn}_{0.3} \mathrm{~S} /$ $\mathrm{Mn}^{2+}$ is plotted as a function of temperature. The lifetime of the $\mathrm{Mn}^{2+}$ emission in nanocrystalline $\mathrm{Cd}_{0.7} \mathrm{Zn}_{0.3} \mathrm{~S} / \mathrm{Mn}^{2+}$ measured at $4 \mathrm{~K}$ is about the same as for $\mathrm{CdS} / \mathrm{Mn}^{2+}$ $(\sim 1 \mathrm{~ms})$. With increasing temperature the lifetime decreases. However, as it is clear from Fig. 8, the quenching rate of the lifetime of the $\mathrm{Mn}^{2+}$ emission is lower in nanocrystalline $\mathrm{Cd}_{0.7} \mathrm{Zn}_{0.3} \mathrm{~S} / \mathrm{Mn}^{2+}$ than in nanocrystalline $\mathrm{CdS} / \mathrm{Mn}^{2+}$, indicating that the temperature induced (intrinsic) quenching of the $\mathrm{Mn}^{2+}$ emission does not occur in $\mathrm{Cd}_{0.7} \mathrm{Zn}_{0.3} \mathrm{~S} / \mathrm{Mn}^{2+}$ below room temperature. This may be related to the wider band gap in $\mathrm{Cd}_{0.7} \mathrm{Zn}_{0.3} \mathrm{~S} / \mathrm{Mn}^{2+}$ or the influence of smaller $\mathrm{Zn}^{2+}$ ions. Further research is required to resolve this issue.

\section{Conclusion}

Temperature dependent luminescence and luminescence lifetime measurements are reported for nanocrystalline $\mathrm{CdS} / \mathrm{Mn}^{2+}$. Based on the results a model is proposed in which shallow traps are involved in the energy transfer process from the exciton to $\mathrm{Mn}^{2+}$.

\section{References}

[1] R. Rosetti, R. Hull, J.M. Gibson, L.E. Brus, J. Chem. Phys. 82 (1985) 552.

[2] L. Brus, J. Phys. Chem. 90 (1986) 2555.

[3] A. Henglein, Chem. Rev. 89 (1989) 1861. 
[4] Y. Wang, N. Herron, J. Phys. Chem. 95 (1991) 525.

[5] A.P. Alivistatos, J. Phys. Chem. 100 (1996) 13226.

[6] R.N. Bhargava, D. Gallagher, Phys. Rev. Lett. 72 (1994) 416.

[7] A.A. Bol, A. Meijerink, Phys. Rev. B 58 (1998) R15997.

[8] N. Murase, R. Jagannathan, Y. Kanematsu, M. Watanabe, A. Kurita, K. Hirata, T. Yazawa, T. Kushida, J. Phys. Chem. B 103 (1999) 754.

[9] M.A. Chamarro, V. Voliotis, R. Grousson, P. Lavallard, T. Gacoin, G. Counio, J.P. Boilot, R. Cases, J. Cryst. Growth 159 (1996) 853.

[10] G. Counio, T. Gacoin, J.P. Boilot, J. Phys. Chem. B 102 (1998) 5257.

[11] M.V. Artemyev, L.I. Gurinovich, A.P. Stupak, S.V. Gaponenko, Phys. Stat. Sol. (b) 224 (2001) 191.

[12] L. Levy, D. Ingert, N. Feltin, M.-P. Pileni, Adv. Mater. 10 (1998) 53.

[13] S. Liu, F. Liu, H. Guo, Z. Zhang, Z. Wang, Solid State Commun. 115 (2000) 615.

[14] A.A. Bol, A. Meijerink, Phys. Stat. Solidi. B 224 (2001) 173.

[15] B.D. Cullity, Elements of X-ray Diffraction, Addison-Wesley, Massachusetts, 1978, p. 102.

[16] S. Shionoya, in: W.M. Yen, S. Shionoya (Eds.), Phosphor Handbook, CRC Press, Boca Raton, 1999, Chapter 3.
[17] D.C. Curie, R. Acad. Sci. 258 (1964) 3269.

[18] F. Henneberger, J. Puls, C. Spiegelburg, A. Scuelzgen, H. Rossman, V. Jungnickel, A.L. Ekimov, Semicond. Sci. Technol. 6 (1991) A41.

[19] A. Van Dijken, Optical Properties and Quantum Confinement of Nanocrystalline II-VI Semiconductor Particles, Chapter 3, Thesis, Utrecht University, 1999.

[20] L. Levy, D. Ingert, N. Feltin, M.P. Pileni, J. Cryst. Growth 184-185 (1998) 377.

[21] C. Ehrlich, W. Busse, H.-E. Gumlich, D. Tschierse, J. Cryst. Growth 72 (1985) 371.

[22] D.R. Lide (Eds.), Handbook of Chemistry and Physics, 74th ed., CRC Press, Boca Raton, 1993.

[23] G.G. Guilbalt (Eds.), Fluorescence: Theory, Instrumentation and Practice, Marcel Dekker, New York, 1967, p. 88.

[24] M. Braun, W. Tuffentsammer, H. Wachtel, H.C. Wolf, Chem. Phys. Lett. 307 (1999) 373.

[25] S.I. Klink, L. Grave, D.N. Reinhoudt, F.C.J.M. Van Veggel, M.H.V. Werts, F.A.J. Geurts, J.W. Hofstraat, J. Phys. Chem. A 104 (2000) 5457.

[26] F. Schael, H.-G. Loehmannsroeben, Chem. Phys. 206 (1996) 193. 